\title{
Control of hypoxia-induced tumor cell adhesion by cytophilic human catalase.
}

\section{$\operatorname{AUTHOR}(\mathrm{S}):$}

Yata, Tomoya; Nishikawa, Makiya; Nishizaki, Chika; Oku, Masahide; Yurimoto, Hiroya; Sakai, Yasuyoshi; Takakura, Yoshinobu

\section{CITATION:}

Yata, Tomoya ...[et al]. Control of hypoxia-induced tumor cell adhesion by cytophilic human catalase.. Free radical biology \& medicine 2009, 47(12): 1772-1778

\section{ISSUE DATE:}

2009-12-15

URL:

http://hdl.handle.net/2433/91262

\section{RIGHT:}

c 2009 Elsevier Inc. All rights reserved.; This is not the published version. Please cite only the published version.; この論文は出版社版でありませ ん。引用の際には出版社版をご確認ご利用ください。 


\section{Control of hypoxia-induced tumor cell adhesion by cytophilic human catalase}

Tomoya Yata ${ }^{\mathrm{a}}$, Makiya Nishikawa ${ }^{\mathrm{a}}$, Chika Nishizaki ${ }^{\mathrm{a}}$, Masahide Oku ${ }^{\mathrm{b}}$, Hiroya Yurimoto $^{\mathrm{b}}$, Yasuyoshi Sakai ${ }^{\mathrm{b}}$, Yoshinobu Takakura $^{\mathrm{a}}$

a: Department of Biopharmaceutics and Drug Metabolism, Graduate School of Pharmaceutical Science, Kyoto University, Sakyo-ku, Kyoto 606-8501, Sakyo-ku, Japan

b: Division of Applied Life Sciences, Graduate School of Agriculture, Kyoto University, Sakyo-ku, Kyoto 606-8502, Japan

Correspondence to: Makiya Nishikawa, Ph.D., Department of Biopharmaceutics and Drug Metabolism, Graduate School of Pharmaceutical Sciences, Kyoto University, Sakyo-ku, Kyoto, Japan.

Phone: +81-75-753-4580; Fax: +81-75-753-4614; E-mail: makiya@pharm.kyoto-u.ac.jp 


\section{Abstract}

Hypoxia-induced reactive oxygen species (ROS)-mediated expression of a variety of genes in endothelial cells has been suggested to be involved in abnormal cell adhesion.

To prevent this by accelerated binding of catalase to endothelial cells, human catalase (hCAT), an enzyme catalyzing the decomposition of hydrogen peroxide, was fused with three repeats of arginine-glycine-aspartic acid peptide or nona arginine peptide at the C-terminal to obtain hCAT-(RGD)3 and hCAT-R9, respectively. Human CAT and its derivatives were expressed in yeast Pichia pastoris and purified. The specific activity and secondary structure of hCAT-(RGD)3 and hCAT-R9 were close to those of hCAT, but these derivatives showed higher binding to mouse aortic vascular endothelial cell line MAEC than hCAT, indicating that they are cytophilic derivatives. Hypoxic treatment of MAEC increased the intracellular ROS level, the binding of mouse melanoma cells, and the activity of transcription factors, hypoxia inducible factor- 1 and nuclear factor-кB. hCAT-(RGD)3 or hCAT-R9 efficiently inhibited these changes compared with hCAT. These results indicate that cytophilic hCAT-(RGD)3 and hCAT-R9 are effective in inhibiting hypoxia-induced tumor cell adhesion to endothelial cells.

Keywords: recombinant human catalase; abnormal cell adhesion; reactive oxygen species; hypoxia; free radicals 


\section{Introduction}

Vascular endothelium is a monolayer lining the interior surface of blood vessels, which forms an interface between blood and tissue. Dynamically responding to changes in environmental factors, such as oxygen tension, cytokines and growth factors, endothelial cells play a pivotal role in maintaining physiological homeostasis [1].

Abnormal cell adhesion to vascular endothelium is observed in a wide range of pathological situations, including arteriosclerosis, thrombosis and tumor metastasis [2-4]. Under these pathological conditions, local blood flow is impaired to induce microenvironmental changes that lead to the imbalance of oxygen demand and supply, and resulting hypoxia [5]. Endothelium that has experienced hypoxia can be the 'soil' for tumor metastasis, because cells, including endothelial cells, increase the transcription of a variety of genes for adaptation to hypoxia [4]. An increasing body of evidence suggests that ROS play a central role in controlling hypoxia-induced transcription [6, 7]. Therefore, eliminating ROS in endothelial cells can be an efficient approach to controlling abnormal cell adhesion to endothelium. Catalase is an antioxidant enzyme that catalyzes the degradation of hydrogen peroxide, ROS with a long half-life. However, previous studies have demonstrated that catalase poorly interacts with cells [8], so that any approaches to increasing its binding to cells could increase its therapeutic potential in a wide range of disease conditions.

A variety of molecules, including integrins and other adhesion molecules, are 
expressed on the surface of endothelial cells [9]. In addition, negative charge of cell surface provides a vast surface area for binding of cationic compounds [9]. In this study, two types of cytophilic human catalase (hCAT) derivatives were newly designed: one is hCAT fused with a arginine-glycine-aspartic acid (RGD) peptide, which is a well-known ligand for $\alpha_{v} \beta_{3}$ integrin, and the other is one fused with a nona arginine (R9) peptide, a cationic peptide. hCAT and its derivatives were expressed in P. pastoris, and their activity to inhibit hypoxia-induced tumor cell adhesion was examined. 


\section{Materials and Methods}

Cell culture

A mouse aortic vascular endothelial cell line (MAEC), a gift from Professor Ichiro Saito

(Department of Pathology, Tsurumi University School of Dental Medicine, Yokohama, Japan), was cultured as previously reported [10]. B16-BL6/Luc [11] and colon26/Luc [12], clones of murine melanoma B16-BL6 and murine colon carcinoma colon26 that stably express the firefly luciferase, were grown as reported previously. A murine Lewis lung cancer (LLC) was cultured as reported previously [13]. To establish LLC/Luc, LLC was transfected with pCMV-Luc [14] using Lipofectamine 2000 (Invitrogen, Carlsbad, CA, USA) according to the manufacturer's instruction. Cell culture under hypoxic conditions (8 \% oxygen) was carried out using an AnaeroPack (Mitsubishi Gas Chemical Co., Tokyo, Japan).

Expression and purification of recombinant human catalase derivatives The pCMV6-Entry vector containing the genomic Homo sapiens catalase (NM_001752) cDNA was purchased from OriGene Technologies Inc. (Rockville, MD, USA). Oligonucleotides corresponding to the amino acid sequence RGDRGDRGD (5’-AGAGGTGATAGAGGCGACAGAGGTGAC-3’) or RRRRRRRRR (5’-AGAAGAAGGAGAAGAAGGAGAAGGAGA-3’) were purchased from Greiner Bio-One Co. Ltd. (Tokyo, Japan). For the expression of glutathione S-transferase 
(GST)-fusion proteins in the cytoplasm of P. pastoris, pNT401 vector was first constructed from pIB2 vector [15]; DNA sequence encoding GST was PCR-amplified and cloned immediately downstream of glyceraldehyde-3-phosphate dehydrogenase promoter within the parental vector. A PCR fragment of human catalase cDNA was digested with BglII and $\mathrm{XbaI}$ and inserted into BamHI-SpeI site of pNT401 expression vector. To construct plasmid vectors expressing hCAT-(RGD)3 or hCAT-R9, the DNA sequence corresponding to the C-terminal 11 amino acid residues (SHLAAREKANL) of human catalase, which contains a peroxisomal sorting signal [16, 17], was replaced with that corresponding to each peptide.

The plasmid constructs were linearized with SalI. P. pastoris yeast SMD1168 was transformed by electroporation at $1.5 \mathrm{kV}, 25 \mu \mathrm{F}, 200 \Omega$. Minimal SD agar plates (2 \% glucose, $0.5 \%$ ammonium sulfate, $0.17 \%$ yeast nitrogen base w/o amino acids and ammonium sulfate, $2 \%$ agar) were used for the selection of P. pastoris transformants. Single colonies were picked and inoculated into $5 \mathrm{~mL}$ of YPD medium (1 \% yeast extract, $2 \%$ peptone, $2 \%$ glucose) and grown at $30{ }^{\circ} \mathrm{C}$ in a bio-shaker with shaking at $250 \mathrm{rpm}$ for $36 \mathrm{hr}$. A $2.5 \mathrm{~mL}$ aliquot of this suspension was inoculated to 500 $\mathrm{mL}$ of YPD medium in $3 \mathrm{~L}$ flask, and the culture was grown for $24 \mathrm{hr}$. The cells were harvested with $2000 \times$ g centrifugation, and disrupted using a French Press at 2,000 psi. The clarified supernatants of cell lysates containing hCAT, hCAT-(RGD)3 or hCAT-R9 were loaded onto a glutathione sepharose column (GE Healthcare, U.K.), and these 
proteins were eluted by applying PreScission protease (GE Healthcare) in $50 \mathrm{mM}$

Tris-HCl solution ( $\mathrm{pH}$ 7.5). After concentration by ultrafiltration, the solvent of each elute was changed to water. The purified catalase derivatives were stored at $-20{ }^{\circ} \mathrm{C}$ until use.

Determination of catalase specific activity

Protein concentration was quantified using a BCA Protein Assay Kit (Pierce, Rockford, IL, USA). Each catalase derivative $(0.04 \mu \mathrm{g})$ was added to $25 \mathrm{mM}$ phosphate buffer ( $\mathrm{pH}$ 7.0) containing $10 \mathrm{mM}$ hydrogen peroxide, and the decomposition of hydrogen peroxide was monitored spectrophotometrically at $240 \mathrm{~nm}$. Samples were used without any separation of active (heme-containing) and inactive (heme free) forms. Bovine liver catalase (50,400 U/mg protein; Sigma Aldlich, USA) was used as a standard. Each sample was measured in five replicates and their averages were employed.

Measurement of circular dichroism

Circular dichroism (CD) spectra were recorded using a JASCO-820 type spectropolarimeter (JASCO, Tokyo, Japan) at $4{ }^{\circ} \mathrm{C}$. For calculation of the mean residue ellipticity [ $\theta]$, the molecular mass of the catalase derivatives was assumed to be as 240 kDa [8]. Far-UV (wavelength 200-250 nm) CD spectra were recorded at a protein concentration of $15 \mu \mathrm{M}$ in Tris buffer (50 mM Tris-HCl (pH 7.5), $150 \mathrm{mM} \mathrm{NaCl}$ ). 
Interaction of catalase derivatives with endothelial cells

MAEC seeded on 24 well plates at a density of $1.0 \times 10^{5}$ cells/well were exposed to Medium 199 (Gibco, USA) containing one of the catalase derivatives at a concentration of $100 \mathrm{U} / \mathrm{mL}$ for $30 \mathrm{~min}$ at $4{ }^{\circ} \mathrm{C}$ or $37^{\circ} \mathrm{C}$. Then, the cells were washed with PBS and lysed with a lysis buffer (0.05 \% Triton-X, 2 mM EDTA, 0.1 M Tris-HCl (pH 7.8)). The catalase activity of cell lysates was determined as described above.

Intracellular ROS production under hypoxic conditions Intracellular ROS production was detected using $\mathrm{CM}-\mathrm{H}_{2}$ DCFDA (Invitrogen). MAEC were treated with $5 \mu \mathrm{M}$ CM- $\mathrm{H}_{2}$ DCFDA for $1 \mathrm{hr}$, and then were cultured under hypoxic conditions of $8 \%$ oxygen. The fluorescence intensity was measured using a 1420 Multilabel counter (PerkinEimer, USA) at an excitation wavelength of $485 \mathrm{~nm}$ and an emission wavelength of $530 \mathrm{~nm}$.

Measurement of luciferase activity

Cells were lysed with the lysis buffer. Twenty microliters of the lysate was mixed with $20 \mu \mathrm{L}$ luciferase assay buffer (Picagene, Tokyo Ink, Tokyo, Japan) and the produced light was measured using a luminometer (Lumat LB 9507, EG\&G Berthold, Bad Wildbad, Germany). 


\section{Cell adhesion assay}

To examine the effect of hydrogen peroxide on tumor cell adhesion, MAEC $\left(1.0 \times 10^{5}\right.$ cells/well) were seeded on 24 well plates, added with hydrogen peroxide at a final concentration of 0 to $100 \mu \mathrm{M}$, and incubated for $6 \mathrm{~h}$. Then, tumor cells (B16-BL6/Luc, LLC/Luc and colon26/Luc) at a density of $1.0 \times 10^{4}$ cells/well were added into each well containing the MAEC monolayer and incubated for $3 \mathrm{hr}$. Then, non-attached cells were washed out with PBS, and the remaining adherent cells were lysed with the lysis buffer. The luciferase activity of the lysates was measured as described above. Separately, MAEC were incubated under normoxic or hypoxic conditions for $6 \mathrm{hr}$. Then, tumor cells were added and their adhesion was examined as above.

Transcription factor dependent reporter gene assay

MAEC seeded on 24 well plates at a density of $1.0 \times 10^{5}$ cells/well were transfected with pHRE-Luc [18], pNF-кB-Luc, or pAP-1-Luc (Stratagene, La Jolla, CA, USA) using Lipofectamine 2000 as described above. After incubation under hypoxic or normoxic conditions for $6 \mathrm{hr}$, cells were lysed with the lysis buffer. The luciferase activity of the cell lysates was measured as described above.

mRNA quantification 
Total RNA was isolated from MAEC $\left(2.0 \times 10^{5}\right.$ cells $)$ after incubation under hypoxic or normoxic conditions for $6 \mathrm{hr}$, and the mRNA expression of intercellular adhesion molecule-1 (ICAM-1) and vascular cell adhesion molecule-1 (VCAM-1) in MAEC was estimated by real-time quantitative PCR using a LightCycler system (Roche Diagnostics, Mannheim, Germany). The mRNA expression of the target genes was normalized to the mRNA level of GAPDH. The primer sequences for RT-PCR were as follows, ICAM-1: forward 5'-GGGAATGTCACCAGGAAT-3', reverse 5’-TCCTGAGCCTTCTGTAACTTG-3', VCAM-1: forward 5’-CGGCATATACGAGTGTGAATC-3’, reverse 5’-ATCCCGATGGCAGGTATT-3’, GAPDH: forward 5’-TCTCCTGCGACTTCAACA-3', reverse 5’-GCTGTAGCCGTATTCATTGT-3’.

Statistical analysis

Differences were statistically evaluated by one-way ANOVA followed by the Tukey-Kramer multiple comparison test, and the level of statistical significance was set at $\mathrm{P}<0.05$. 


\section{Results}

\section{Characterization of catalase derivatives}

Figure 1 shows the schematic representation of human catalase derivatives: hCAT, hCAT-(RGD)3 and hCAT-R9. Three constructs were expressed in P. pastoris, and purified as described in the Materials \& Methods. Figure 2A shows the SDS-PAGE patterns of the human catalase derivatives. Each sample showed a single band of about $60 \mathrm{kDa}$, indicating that the catalase derivatives were adequately purified. The far-CD spectra of hCAT-(RGD)3 and hCAT-R9 were similar to that of hCAT (Figure 2B), suggesting that the fusion of peptides hardly changed the secondary structure of human catalase. Figure 2C shows the time-dependent decomposition of hydrogen peroxide by the human catalase derivatives. The activities of hCAT, hCAT-(RGD)3 and hCAT-R9 ware 20,000, 19,500 and 24,300 units/mg protein, respectively, indicating that the fusion hardly reduced the specific activity of human catalase. These results are in a good agreement with the previous finding that the modification of C-terminus of catalase hardly influenced its activity [19].

Next, the cellular association of catalase derivatives in MAEC was examined at $37^{\circ} \mathrm{C}$ or $4{ }^{\circ} \mathrm{C}$. The activity to degrade hydrogen peroxide in cellular fractions was used to estimate the amount of catalase derivatives associated with cells. Cells untreated with any catalase derivative had a very low activity of $0.85 \pm 0.003 \mathrm{mU} / 10^{5}$ cells. The activity of cells was increased to $94.2 \pm 14.3 \mathrm{mU} / 10^{5}$ cells when cells were incubated 
with hCAT for $30 \mathrm{~min}$ at $37^{\circ} \mathrm{C}$, indicating hCAT is associated with cells. The activity of cells treated with hCAT-(RGD)3 or hCAT-R9 at $37^{\circ} \mathrm{C}$ was significantly higher (217 \pm 31 and $261 \pm 9 \mathrm{mU} / 10^{5}$ cells, respectively) than that treated with hCAT. At $4{ }^{\circ} \mathrm{C}$, a temperature at which internalization is essentially blocked, the activity of cells added with hCAT-R9 was significantly lower than that at $37^{\circ} \mathrm{C}$. On the other hand, the activities of cells added with hCAT or hCAT-(RGD)3 were not significantly different between the temperatures. These results suggest that the mechanisms of increased interaction of catalase derivatives with MAEC are different between hCAT-(RGD)3 and hCAT-R9.

Effect of catalase derivatives on intracellular ROS generation in MAEC under hypoxic conditions

The levels of intracellular ROS in MAEC were monitored using an ROS-sensitive probe. The fluorescence intensity increased significantly at 3 to $9 \mathrm{hr}$ after exposure to hypoxia (Figure 4). Treatment of cells with hCAT before exposure to hypoxia slightly reduced the level of intracellular ROS in MAEC. Greater reduction was observed in MAEC treated with hCAT-(RGD)3 or hCAT-R9. The addition of 10 U/mL hCAT-(RGD)3 or hCAT-R9 was more effective in inhibiting the increase of the intracellular ROS than the addition of $100 \mathrm{U} / \mathrm{mL}$ hCAT (Figure 4). These results suggest that intracellular ROS generation in MAEC is induced soon after exposure to hypoxic stress, and can be 
efficiently eliminated by catalase derivatives, especially by hCAT-(RGD)3 and hCAT-R9, in a dose-dependent manner.

\section{Adhesion of tumor cells to MAEC}

Next, we investigated whether hypoxia induces the adhesion of tumor cells to endothelial cells. Preincubation of MAEC with hydrogen peroxide significantly increased the adhesion of B16-BL6/Luc, colon26/Luc and LLC/Luc to MAEC (Figure 5A). The number of cells bound to MAEC tended to increase depending on the concentration of hydrogen peroxide from 25 to $100 \mu \mathrm{M}$. Separately, MAEC were incubated under hypoxic or normoxic conditions, and then adhesion of tumor cells was examined. Again, an increased binding of tumor cells to MAEC was observed under hypoxic conditions compared with under normoxia (Figure 5B). Then, the effects of catalase derivatives on the hypoxia-induced adhesion of B16-BL6/Luc were examined by treating MAEC with catalase derivatives at a concentration of 1 or $100 \mathrm{U} / \mathrm{mL}$. hCAT reduced the hypoxia-induced cell adhesion (Figure 6). Under the same condition, hCAT-(RGD)3 and hCAT-R9 showed a greater inhibitory effect on the hypoxia-induced tumor cell adhesion than hCAT. Significantly lower numbers of tumor cells were bound to MAEC treated with hCAT-(RGD)3 or hCAT-R9 ( $\mathrm{p}<0.05$ compared with the same concentration of hCAT). The effects of catalase derivatives on tumor cell adhesion under normoxic conditions were less apparent than those under hypoxia, suggesting that 
catalase derivatives inhibit hypoxia-induced, hydrogen peroxide-mediated tumor cell adhesion under hypoxic conditions.

Effect of catalase derivatives on transcription factor activity in MAEC under hypoxic conditions

To investigate the mechanism of inhibitory effect of catalase derivatives on hypoxia-induced cell adhesion, the activity of transcription factors HIF-1, NF-кB and AP-1 was estimated using pHRE-Luc, pNF-кB-Luc and pAP-1-Luc, respectively. The addition of hydrogen peroxide to cells increased the luciferase activity in cells (data not shown), suggesting that the transcription factors are activated by the addition of hydrogen peroxide. Culture of MAEC under hypoxic conditions induced significant

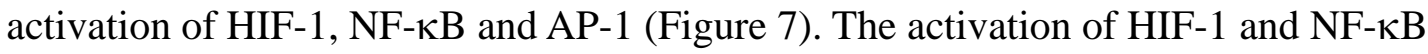
was inhibited by catalase derivatives, especially by hCAT-(RGD)3 or hCAT-R9. Strikingly, pre-treatment of $100 \mathrm{U} / \mathrm{mL}$ of hCAT-R9 almost completely inhibited the activation of HIF-1, NF-кB and AP-1. In accordance with the results of tumor cell adhesion (Figure 6), the effects of catalase derivatives under normoxic conditions were less significant than those under hypoxic conditions.

mRNA expression of adhesion molecules under hypoxic conditions Finally, the changes in mRNA level of cell adhesion molecules that have reported to be 
induced by HIF-1 or NF-кB [20] were examined using RT-PCR. The expression of ICAM-1 was induced in MAEC under hypoxia (Figure 8), but that of VCAM-1 was hardly changed (data not shown). The increase in the mRNA level of ICAM-1 was reduced by all catalase derivatives examined. 


\section{Discussion}

Antioxidant enzymes including catalase have been believed to be promising therapeutic agents for a variety of human diseases related to oxidative stress, but the poor cell affinity of these enzymes has been a major obstacle in developing them as agents to protect cells and tissues from oxidative damage [8]. Recent studies have demonstrated that targeted or sustained delivery of bovine catalase by chemical modification is a therapeutic approach for ROS-mediated diseases, such as hepatic ischemia/reperfusion injury, cisplatin-induced nephrotoxicity and tumor metastasis [21-24]. However, chemical modification of protein, in general, has some disadvantages, such as productivity and uniformity of the products, compared with genetic modification from a viewpoint of clinical application. Furthermore, heterologous proteins, such as bovine catalase, can be immunogenic, so that the use of human catalase instead of bovine origin will reduce the possibility of antibody production after administration to patients [25]. In this study, we selected genetic engineering technique for modification of human catalase.

Previous studies have reported that enhanced delivery of biologically active proteins to cells is possible by using peptides that have high affinity with cells, including RGD peptide and oligoarginine peptide [26-28]. RGD motifs are found in many extracellular matrix proteins, and are recognized by and bound to integrins, a family of cell adhesion receptors expressed on the surface of various cells [29]. On the 
other hand, oligoarginine peptide is a short repeat of basic amino acid arginine, and it has been reported not only to bind to negatively charged cell membranes, but also to initiate macropinocytosis, a special form of endocytosis, which facilitates the internalization of surface-bound compounds [30]. In order to increase the affinity of catalase with endothelial cells, the C-terminus of catalase was fused with (RGD)3 peptide or R9 peptide. It has been reported that three repeat of RGD has higher affinity with integrins than monomeric RGD [29, 31], so that the three repeat of the peptide was used for the construction of a catalase derivative containing RGD peptide. Both hCAT-(RGD)3 and hCAT-R9 showed an increased affinity for MAEC, but their cellular distribution was suggested to be different each other (Figure 3); hCAT-(RGD)3 could be bound to cell surface, whereas a part of hCAT-R9 was considered to be internalized during the 30-min incubation. R9 peptide fused to C-terminus of catalase might initiate the active cellular uptake mechanism as suggested in a previous report [30]. Although cellular distribution of these two types of catalase derivatives can be different each other, both eliminated intracellular ROS in MAEC, and inhibited the activation of HIF-1 and NF-кB under hypoxic condition. Because hCAT-(RGD)3 or hCAT-R9 was estimated more than 10 times effective than hCAT, the cytophilic nature of hCAT-(RGD)3 and hCAT-R9 is highly efficient for the removal of hydrogen peroxide generated in endothelial cells under hypoxic conditions. Two types of cytophilic catalase derivatives showed somewhat different intracellular distribution, but their inhibitory effects against 
tumor cell adhesion were comparable. These results would be explained by the fact that hydrogen peroxide easily passes through cellular membranes.

The present study demonstrated that the cytophilic catalase derivatives have high binding affinity to MAEC. However, these results do not mean that their inhibition of ROS-mediated events in MAEC is the only mechanism for inhibiting tumor cell adhesion. The intracellular ROS level in tumor cells would be increased by several mechanisms [32]. In addition, the interaction with MAEC would further increase the ROS level in tumor cells. Therefore, cytophilic catalase derivatives bound to MAEC would reduce the ROS level in tumor cells which are interacting with MAEC.

In the design of catalase derivatives, the C-terminus of catalase was selected as the site for fusion with (RGD)3 peptide or R9 peptide. An X-ray structural analysis verified that the C-terminal region of human catalase is exposed on the surface of catalase molecule, and is distant from the active site [33]. In addition, human catalase contains a peroxisomal targeting signal in the C-terminal 11 amino acid sequence [16, 17]. These findings suggest that a peptide fused at the C-terminus is extended outside the protein, and is able to interact with integrins or negatively charged compounds on cell surface, which does not interfere with enzymatic activity of catalase. In fact, the activity and secondary structure of human catalase derivatives were not different from those of wild-type human catalase. These properties were quite contrast to those of chemically modified bovine catalase with an overall positive charge [22]. 
Tumor cells detached from primary tumors would be distributed to a variety of downstream organs via vascular or lymphatic pathways [34]. The adhesion to endothelial cells is the first step in the metastatic processes for tumor cells that have entered the blood circulation. It has been known that surgical removal of primary tumors increases the chance of tumor metastasis through a variety of mechanisms, including the release of tumor cells from primary tumors into circulation.

Administration of cytophilic catalase derivatives before or during surgical removal of primary tumors could reduce the incidence of tumor metastasis through the inhibition of tumor cell adhesion as observed in the present studies using cultured cells.

In conclusion, we have demonstrated that the fusion of (RGD)3 peptide or R9 peptide to the C-terminus of catalase is an efficient method of increasing the cytophilic activity of catalase. Both hCAT-(RGD)3 and hCAT-R9 efficiently inhibited hypoxia-induced cell adhesion through controlling intracellular oxidative stress in MAEC under hypoxic conditions. These results suggest that newly designed cytophilic human catalase derivatives can be effective therapeutic agents for controlling hypoxia-induced tumor cell adhesion. 


\section{Acknowledgement}

This work is supported by a Grant-in-aid for Scientific Research (B) from the Japan

Society for the Promotion of Science (JSPS). 


\section{Abbreviations}

ROS, reactive oxygen species; hCAT, human catalase; hCAT-(RGD)3, human catalase fused with RGDRGDRGD; hCAT-R9, human catalase fused with RRRRRRRRR; CD,

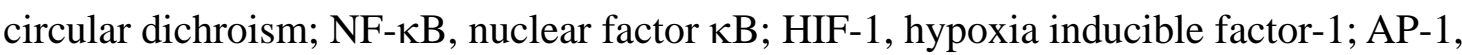
activator protein-1; HRE, hypoxia response element; ICAM-1, intercellular adhesion molecule-1; VCAM-1, vascular cell adhesion molecule-1; GAPDH, glyceraldehyde-3-phosphate dehydrogenase; ; RT-PCR, reverse transcriptional polymerase chain reaction; $P$. pastoris, Pichia pastoris; $\quad$ CM- $\mathrm{H}_{2} \mathrm{DCFDA}$, 5-(and-6)-chloromethyl-2',7'-dichlorodihydrofluorescein diacetate, acetyl ester 


\section{Reference}

[1] Michiels C, Arnould T, Remacle J. Endothelial cell responses to hypoxia: initiation of a cascade of cellular interactions. Biochim Biophys Acta. 1:1-10; 2000.

[2] O'Brien KD, McDonald TO, Chait A, Allen MD, Alpers CE. Neovascular expression of E-selectin, intercellular adhesion molecule-1, and vascular cell adhesion molecule-1 in human atherosclerosis and their relation to intimal leukocyte content. Circulation. 4:672-82; 1996.

[3] Tailor A, Granger DN. Hypercholesterolemia promotes P-selectin-dependent platelet-endothelial cell adhesion in postcapillary venules. Arterioscler Thromb Vasc Biol. 4:675-80; 2003.

[4] Dittmar T, Heyder C, Gloria-Maercker E, Hatzmann W, Zänker KS. Adhesion molecules and chemokines: the navigation system for circulating tumor (stem) cells to metastasize in an organ-specific manner. Clin Exp Metastasis. 1:11-32; 2008.

[5] Vaupel P, Kallinowski F, Okunieff P. Blood flow, oxygen and nutrient supply, and metabolic microenvironment of human tumors: a review. Cancer Res. 23:6449-65; 1989.

[6] Chandel NS, Maltepe E, Goldwasser E, Mathieu CE, Simon MC, Schumacker PT. Mitochondrial reactive oxygen species trigger hypoxia-induced transcription. Proc Natl Acad Sci U S A. 20:11715-20; 1998. Chandel NS, McClintock DS, Feliciano CE, Wood TM, Melendez JA, 
Rodriguez AM, Schumacker PT Reactive oxygen species generated at mitochondrial complex III stabilize hypoxia-inducible factor-1alpha during hypoxia: a mechanism of $\mathrm{O}_{2}$ sensing. J Biol Chem. 33:25130-8; 2000.

[8] Ma SF, Nishikawa M, Katsumi H, Yamashita F, Hashida M. Liver targeting of catalase by cationization for prevention of acute liver failure in mice. J Control Release. 2:273-82; 2006.

[9] Opanasopit P, Nishikawa M, Hashida M. Factors affecting drug and gene delivery: effects of interaction with blood components. Crit Rev Ther Drug Carrier Syst. 3:191-233; 2002.

[10] Nishiyama T, Mishima K, Ide F, Yamada K, Obara K, Sato A, Hitosugi N, Inoue H, Tsubota K, Saito I. Functional analysis of an established mouse vascular endothelial cell line. J Vasc Res. 2:138-48; 2007.

[11] Hyoudou K, Nishikawa M, Umeyama Y, Kobayashi Y, Yamashita F, Hashida M. Inhibition of metastatic tumor growth in mouse lung by repeated administration of polyethylene glycol-conjugated catalase: quantitative analysis with firefly luciferase-expressing melanoma cells. Clin Cancer Res. 22:7685-91; 2004.

[12] Hyoudou K, Nishikawa M, Kobayashi Y, Mukai S, Ikemura M, Kuramoto Y, Yamashita F, Hashida M. Inhibition of peritoneal dissemination of tumor cells by cationized catalase in mice. J Control Release. 1:121-7; 2007.

[13] Ogawara K, Un K, Minato K, Tanaka K, Higaki K, Kimura T. Determinants for 
in vivo anti-tumor effects of PEG liposomal doxorubicin: importance of vascular permeability within tumors. Int J Pharm. 1-2:234-40; 2008.

[14] Nomura T, Yasuda K, Yamada T, Okamoto S, Mahato RI, Watanabe Y, Takakura Y, Hashida M. Gene expression and antitumor effects following direct interferon (IFN)-gamma gene transfer with naked plasmid DNA and DC-chol liposome complexes in mice. Gene Ther. 1:121-9; 1999.

[15] Sears IB, O'Connor J, Rossanese OW, Glick BS. A versatile set of vectors for constitutive and regulated gene expression in Pichia pastoris. Yeast. 14:783-790; 1998.

[16] Purdue PE, Lazarow PB. Targeting of human catalase to peroxisomes is dependent upon a novel COOH-terminal peroxisomal targeting sequence. J Cell Biol. 4:849-62; 1996.

[17] Purdue PE, Castro SM, Protopopov V, Lazarow PB Targeting of human catalase to peroxisomes is dependent upon a novel C-terminal peroxisomal targeting sequence. Ann N Y Acad Sci. 804:775-6; 1996.

[18] Takahashi Y, Nishikawa M, Takakura Y. Inhibition of tumor cell growth in the liver by RNA interference-mediated suppression of HIF-1alpha expression in tumor cells and hepatocytes. Gene Ther. 8:572-82; 2008.

[19] Baker RD, Cook CO, Goodwin DC. Properties of catalase-peroxidase lacking its C-terminal domain. Biochem Biophys Res Commun. 3:833-9; 2004.

[20] Turpaev KT. Reactive oxygen species and regulation of gene expression. 
Biochemistry (Mosc). 3:281-92; 2002.

[21] Yabe Y, Kobayashi N, Nishihashi T, Takahashi R, Nishikawa M, Takakura Y,

Hashida M. Prevention of neutrophil-mediated hepatic ischemia/reperfusion injury by superoxide dismutase and catalase derivatives. J Pharmacol Exp Ther. 3:894-9; 2001.

[22] Ma SF, Nishikawa M, Hyoudou K, Takahashi R, Ikemura M, Kobayashi Y, Yamashita F, Hashida M. Combining cisplatin with cationized catalase decreases nephrotoxicity while improving antitumor activity. Kidney Int. 12:1474-82; 2007.

[23] Hyoudou K, Nishikawa M, Kobayashi Y, Umeyama Y, Yamashita F, Hashida M. PEGylated catalase prevents metastatic tumor growth aggravated by tumor removal. Free Radic Biol Med. 9:1449-58; 2006.

[24] Hyoudou K, Nishikawa M, Kobayashi Y, Mukai S, Ikemura M, Kuramoto Y, Yamashita F, Hashida M. Inhibition of peritoneal dissemination of tumor cells by cationized catalase in mice. J Control Release. 1:121-7; 2007.

[25] Dayan AD. Safety evaluation of biological and biotechnology-derived medicines. Toxicology. 1:59-68; 1995.

[26] Schwarze SR, Ho A, Vocero-Akbani A, Dowdy SF. In vivo protein transduction: delivery of a biologically active protein into the mouse. Science.

5433:1569-72; 1999.

[27] Dickerson EB, Akhtar N, Steinberg H, Wang ZY, Lindstrom MJ, Padilla ML, Auerbach R, Helfand SC. Enhancement of the antiangiogenic activity of interleukin-12 
by peptide targeted delivery of the cytokine to alphavbeta3 integrin. Mol Cancer Res. 12:663-73; 2004.

[28] Han K, Jeon MJ, Kim SH, Ki D, Bahn JH, Lee KS, Park J, Choi SY. Efficient intracellular delivery of an exogenous protein GFP with genetically fused basic oligopeptides. Mol Cells. 2:267-71; 2001.

[29] Temming K, Schiffelers RM, Molema G, Kok RJ. RGD-based strategies for selective delivery of therapeutics and imaging agents to the tumour vasculature. Drug Resist Updat. 6:381-402; 2005.

[30] Nakase I, Takeuchi T, Tanaka G, Futaki S. Methodological and cellular aspects that govern the internalization mechanisms of arginine-rich cell-penetrating peptides. Adv Drug Deliv Rev. 4-5:598-607; 2008.

[31] Kurihara H, Nagamune T. Cell adhesion ability of artificial extracellular matrix proteins containing a long repetitive Arg-Gly-Asp sequence. J Biosci Bioeng. 1:82-7; 2005.

[32] Nishikawa M. Reactive oxygen species in tumor metastasis. Cancer Lett. 266:53-9; 2008.

[33] Putnam CD, Arvai AS, Bourne Y, Tainer JA. Active and inhibited human catalase structures: ligand and NADPH binding and catalytic mechanism. J Mol Biol. 1:295-309; 2000.

[34] Engers R, Gabbert HE. Mechanisms of tumor metastasis: cell biological 
aspects and clinical implications. J Cancer Res Clin Oncol. 126:682-92; 2000. 


\section{Figure legends}

Fig. 1: Schematic representation of human catalase derivatives.

The DNA sequence corresponding to the C-terminal 11 amino acids

(SHLAAREKANL) of human catalase, which contains peroxisomal targeting signals, was replaced with oligonucleotides coding RGDRGDRGD or RRRRRRRRR to obtain hCAT-(RGD)3 or hCAT-R9, respectively. The fusion genes were inserted into the pNT401 expression vector and expressed in P. pastoris.

Fig. 2: Characteristics of human catalase derivatives.

(A) Coomassie brilliant blue stained SDS-PAGE gel. Lane 1, Precision Protein Unstained Marker (Bio-Rad); Lane 2, soluble fraction of cell extracts from P. pastoris; Lane 3; purified extracts from $P$. pastoris using glutathione sepharose column. (B) Far-CD spectra of catalase derivatives. The protein concentration was $15 \mathrm{mM}$ in Tris buffer. Key: (solid line), hCAT; (broken line), hCAT-(RGD)3; and (dotted line), hCAT-R9. (C) Time-dependent decomposition of hydrogen peroxide by catalase derivatives. The concentration of remaining hydrogen peroxide was measured spectrophotometrically at $240 \mathrm{~nm}$. Key: (solid line), hCAT; (broken line), hCAT-(RGD)3; and (dotted line), hCAT-R9.

Fig. 3: Catalase activity in MAEC after incubation with catalase derivatives. 
The enzymatic activity of catalase to degrade hydrogen peroxide in MAEC was measured. Key: (closed bar), hCAT; (hatched bar), hCAT-(RGD)3; (open bar), hCAT-R9. Results are expressed as the mean \pm SD of three independent measurements. The catalase activity of untreated MAEC was $0.85 \pm 0.003 \mathrm{mU} / 10^{5}$ cells. ${ }^{*} \mathrm{p}<0.05$ compared with the hCAT-treated group; $\dagger \mathrm{p}<0.05$ compared with the same sample at $37^{\circ} \mathrm{C}$.

Fig. 4: Effect of catalase derivatives on ROS level in MAEC.

Intracellular ROS level was monitored using an ROS-sensitive probe CM- $\mathrm{H}_{2}$ DCFDA.

After exposed to solution containing catalase derivatives for 30 min, MAEC were treated with $5 \mu \mathrm{M} \mathrm{CM}-\mathrm{H}_{2}$ DCFDA for $1 \mathrm{hr}$. Cells were cultured under hypoxic conditions (8 \% oxygen). The fluorescence intensity was measured (excitation $485 \mathrm{~nm}$, emission $530 \mathrm{~nm}$ ), and the ratio to the initial value was plotted against the incubation period as relative fluorescent intensity. Key: $(\boldsymbol{\nabla})$ normoxia, untreated; $(\nabla)$ hypoxia, untreated; ( $)$ hypoxia, hCAT; $(\triangle, \mathbf{\Delta})$ hypoxia, hCAT-RGD; ( $\square, \mathbf{\square})$ hypoxia, hCAT-R9. Concentrations of the derivatives added were 10 (open symbols) or 100 $\mathrm{U} / \mathrm{mL}$ (closed symbols). Results are expressed as the mean of 24 independent measurements. ${ }^{*} \mathrm{p}<0.05$ compared with the hypoxia, untreated group $(\nabla) . \dagger \mathrm{p}<0.05$ compared with the $100 \mathrm{U} / \mathrm{mL}$ hCAT-treated group (O).

Fig. 5: Effect of hydrogen peroxide or hypoxia on tumor cell adhesion to MAEC. 
(A) Effect of hydrogen peroxide on tumor cell adhesion to MAEC. MAEC were cultured in M199 containing 0-100 $\mu \mathrm{M}$ hydrogen peroxide for $6 \mathrm{hr}$, and then co-cultured with B16-BL6/Luc, LLC/Luc or Colon26/Luc for 3 hr. Cell adhesion was evaluated by measuring the luciferase activity of B16-BL6/Luc, LLC/Luc and Colon26/Luc cells bound to MAEC. Results are expressed as mean \pm SD of three independent measurements. ${ }^{*} \mathrm{p}<0.05$ compared with $0 \mu \mathrm{M}$ hydrogen peroxide-treated group. (B) Effect of hypoxia on tumor cell adhesion to MAEC. Results are expressed as mean \pm SD of three independent measurements. ${ }^{*} \mathrm{p}<0.05$ compared with the normoxia group. Key: (Closed bar), B16-BL6/Luc; (hatched bar), LLC/Luc; (open bar), colon26/Luc.

Fig. 6: Effect of catalase derivatives on adhesion of melanoma cells to MAEC. MAEC were exposed to solution containing catalase derivatives for $30 \mathrm{~min}$. Cells were cultured in hypoxia for 6 hr, and then co-cultured with B16-BL6/Luc for 3 hr. Cell adhesion was evaluated by measuring the luciferase activity of B16-BL6/Luc cells bound to MAEC. Results are expressed as mean \pm SD of three independent measurements. Key: (hatched bar), $1 \mathrm{U} / \mathrm{mL}$; (open bar), $100 \mathrm{U} / \mathrm{mL} .{ }^{*} \mathrm{p}<0.05$ compared with the hypoxia, untreated group; \#p<0.05 compared with the hCAT-treated group at the same dose; $\S p<0.05$ compared with the normoxia, untreated group.

Fig. 7: Effect of catalase derivatives on transcription factor activity in MAEC 


\section{under hypoxia.}

MAEC were transfected with pHRE-Luc (A), pNF-kB-Luc (B), or pAP-1-Luc (C).

MAEC were exposed to solution containing catalase derivatives for $30 \mathrm{~min}$. After

incubation under hypoxic conditions for 6 hr, cells were lysed with lysis buffer. Each

transcription factor activity was determined by measuring luciferase activity of the cell

lysates. Results are normalized to the value of the normoxia, untreated group and are expressed as mean \pm SD of three independent measurements. Key: (hatched bar), 1

$\mathrm{U} / \mathrm{mL}$; (horizontal striped bar), $10 \mathrm{U} / \mathrm{mL}$; (open bar), $100 \mathrm{U} / \mathrm{mL} .{ }^{*} \mathrm{p}<0.05$ compared with the hypoxia, untreated group; \#p $<0.05$ compared with the hCAT-treated group at the same dose; $\S p<0.05$ compared with the normoxia, untreated group; $\dagger p<0.05$ compared with the $100 \mathrm{U} / \mathrm{mL}$ hCAT-treated group.

Fig. 8: Effect of catalase derivatives on mRNA expression of ICAM-1 in MAEC under hypoxic conditions.

Total RNA was isolated from MAEC after incubation under hypoxic conditions for $6 \mathrm{hr}$, and the mRNA expression of ICAM-1 in MAEC was estimated by RT-PCR. The mRNA expression of ICAM-1 was normalized to that of $G A P D H$, and the value was then normalized to the value of the normoxia, untreated group. Results are expressed as mean \pm SD of three independent measurements. ${ }^{*} \mathrm{p}<0.05$ compared with the hypoxia, untreated group. 
Fig.1

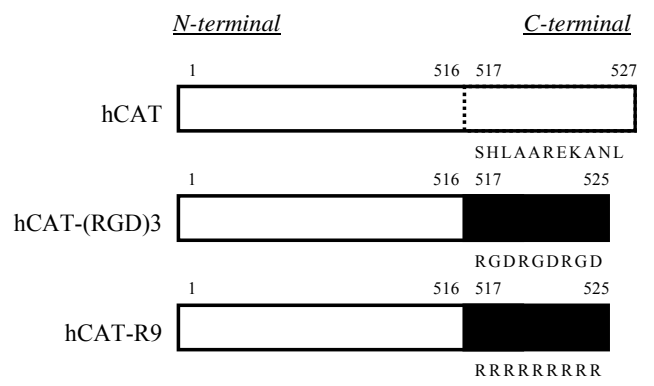


Fig.2
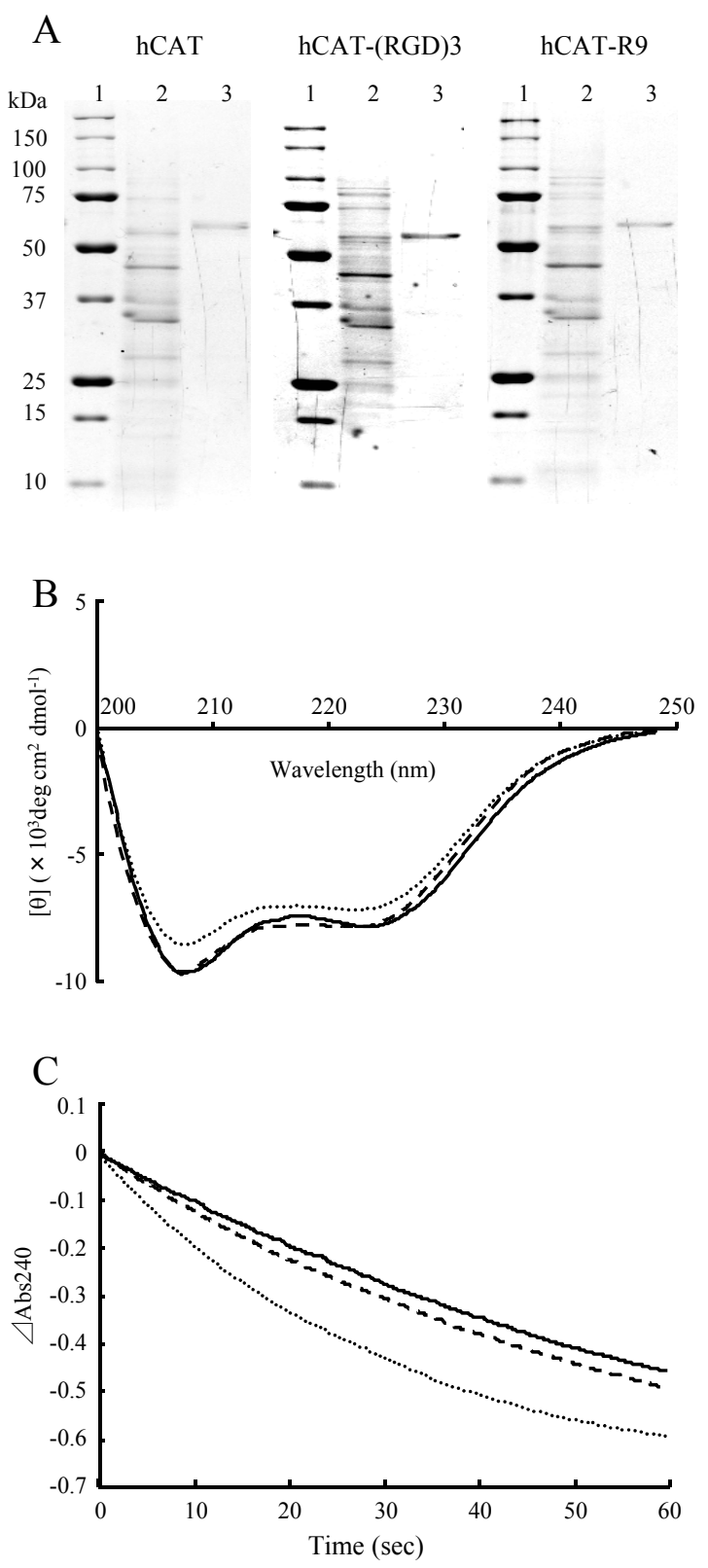
Fig.3

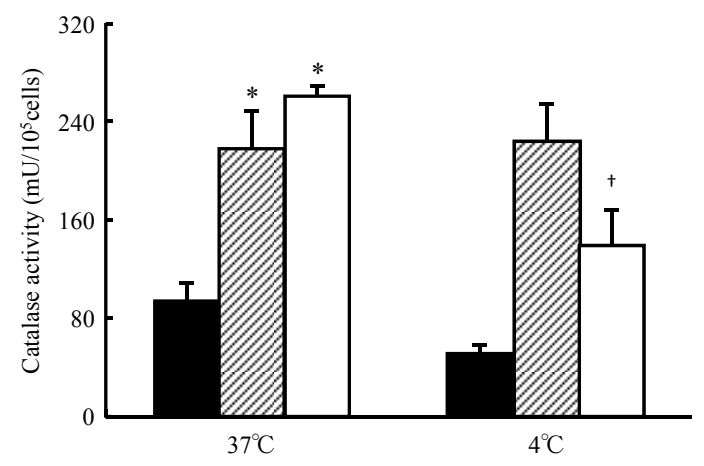


Fig.4

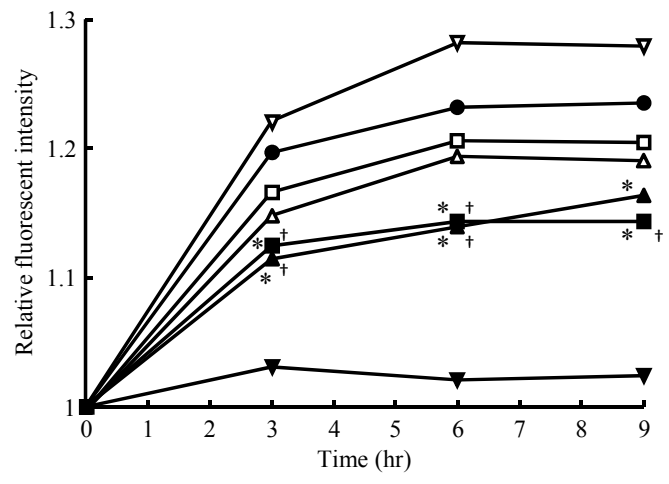


Fig.5
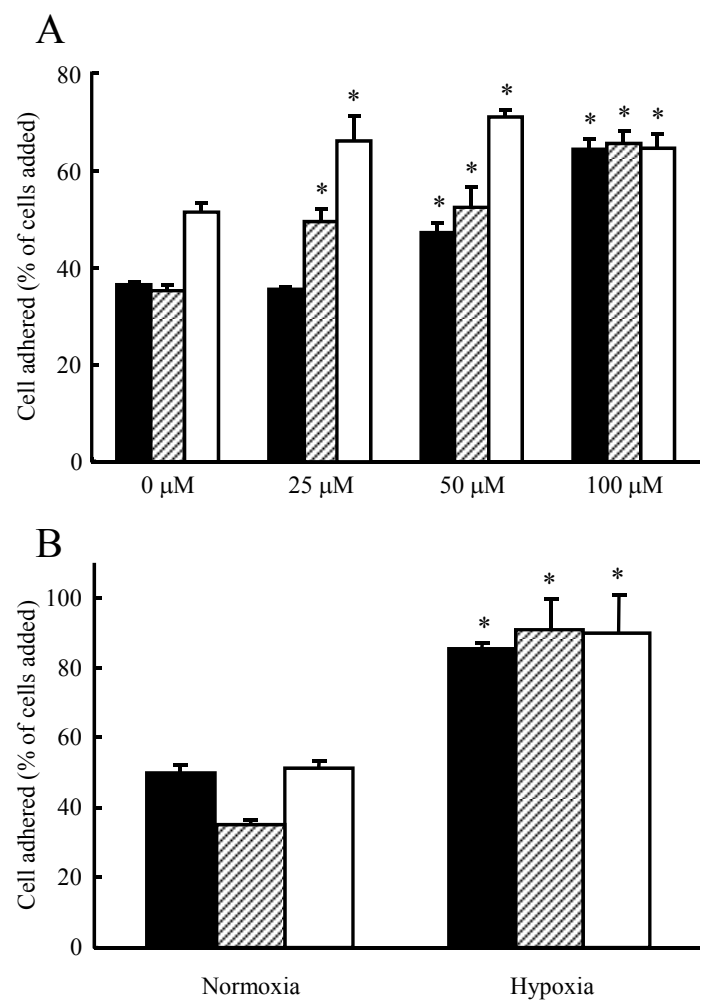
Fig.6

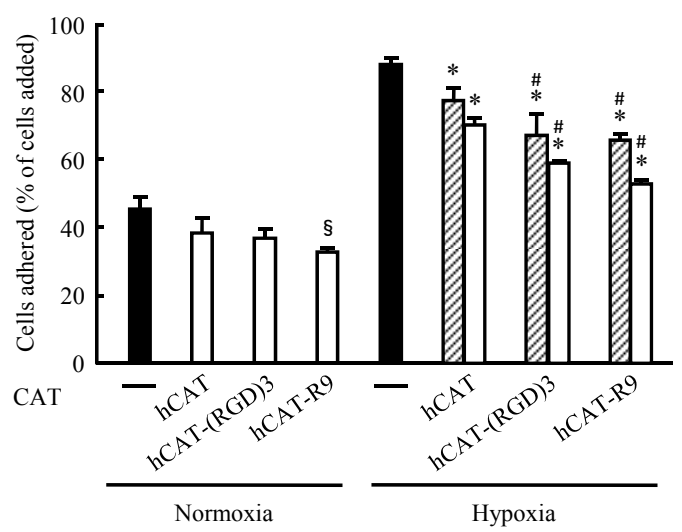


Fig. 7
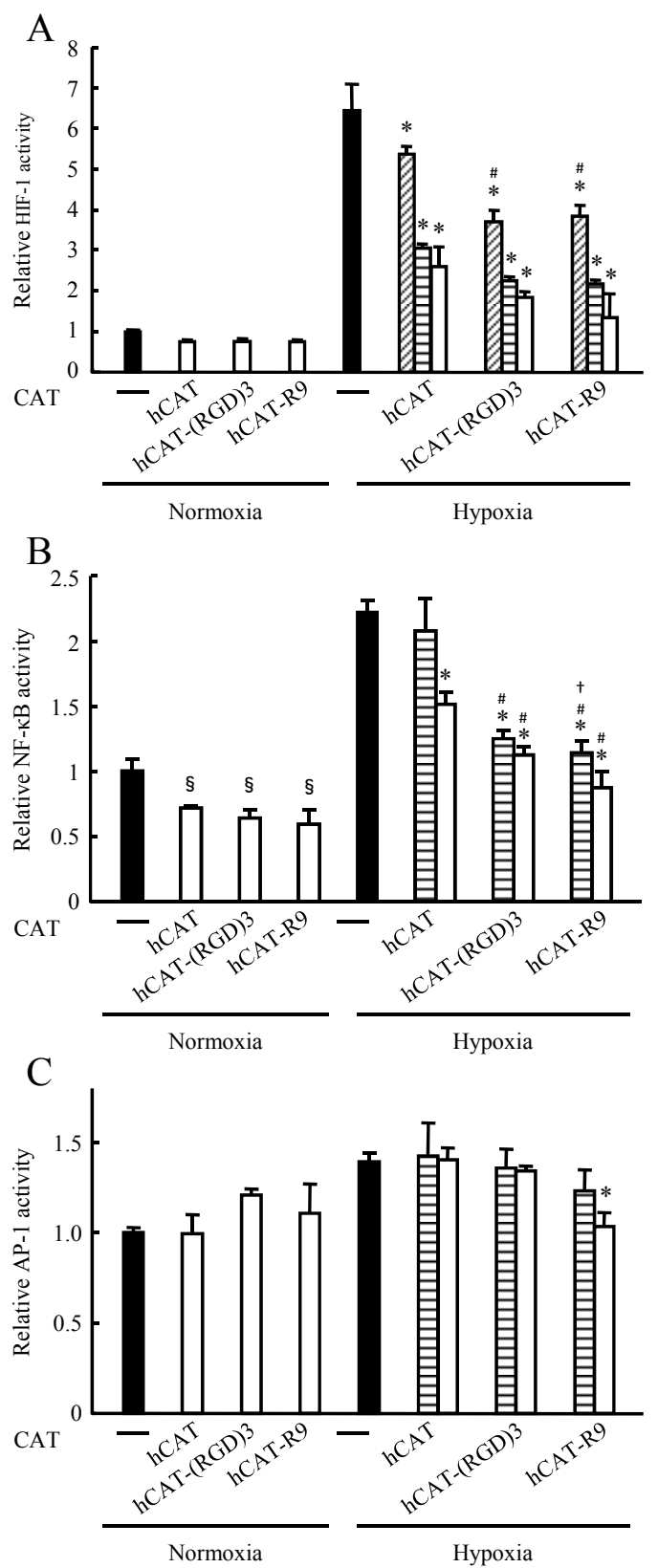
Fig.8

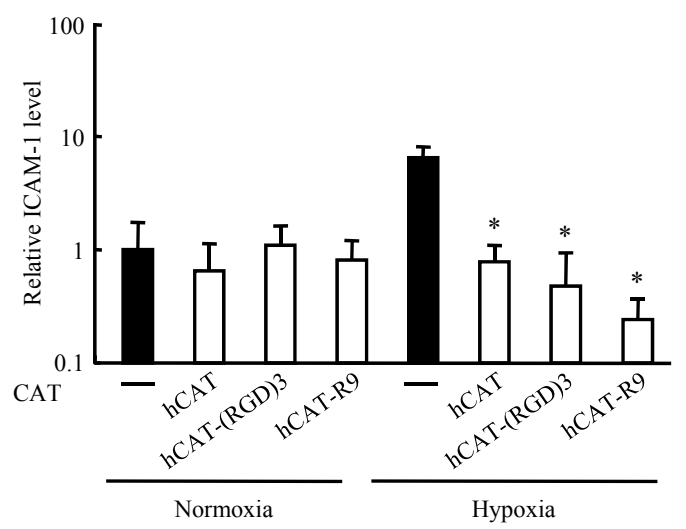

